\title{
Two Finger Matching With Vendor SDK Matchers
}

\author{
C. Watson \\ C. Wilson \\ M. Indovina \\ B. Cochran
}


NISTIR 7249

\title{
Two Finger Matching With Vendor SDK Matchers
}

\author{
C. Watson \\ C. Wilson \\ M. Indovina \\ B. Cochran \\ Image Group \\ Information Technology Laboratroy
}

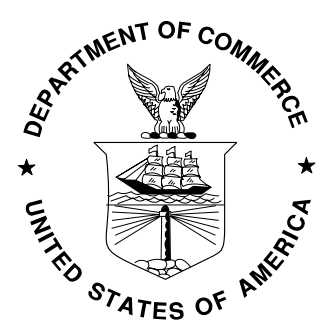

U.S. DEPARTMENT OF COMMERCE Carlos M. Gutierrez, Secretary TECHNOLOGY ADMINISTRATION Michelle O'Neill, Acting Under Secretary of Commerce for Technology NATIONAL INSTITUTE OF STANDARDS AND TECHNOLOGY William A. Jeffrey, Director 


\title{
Two Finger Matching with Vendor SDK Matchers
}

\author{
Craig Watson, Charles Wilson, Mike Indovina, Brian Cochran \\ National Institute of Standards and Technology
}

\begin{abstract}
This report is an extension of the NIST "Studies of one-to-one Fingerprint Matching with Vendor SDK Matchers” which evaluated the accuracy of SDK (Software Development Kit) based COTS (Commercial Off-The-Shelf) fingerprint matching systems for one-toone verification applications [1]. Fingerprint matching systems from twelve vendors were evaluated. The two finger matching evaluation is an extension of that testing used to evaluate the accuracy that can be achieved by combining the index finger scores to achieve a match. These results are based on the SDK matchers provided for the original single finger SDK testing. More details will be available from the Minutiae Exchange Test 2004 (MINEX04) http://fingerprint.nist.gov/MINEX04. The more accurate matchers in the two finger SDK scoring were able to achieve true accept rates (TAR) in the range of .985 - .998 at a false accept rate (FAR) of 0.0001. A copy of this report and appendices is available at http://fingerprint.nist.gov/SDK.
\end{abstract}




\section{Introduction}

The original SDK one-to-one fingerprint matching tests were performed to measure the accuracy of one-to-one fingerprint verification systems[1]. This evaluation is an extension of the one-to-one fingerprint matching tests and is designed to evaluate the matching accuracy that can be achieved by combining scores for the right and left index fingers. These results will support work being done by NIST, Personal Identity Verification (PIV) [3], for Homeland Security Presidential Directive 12 (HSPD12) [2]. This report along with the original single finger SDK testing report will show fingerprint matching accuracies that are obtainable using either single finger or two finger matching strategies. The current two finger testing evaluates fingerprint data from live-scan capture devices that capture each index finger one at a time. Segmented four finger slaps are not evaluated.

This report provides preliminary estimates of the propietary templates tests being done in MINEX04 [4]. Part of the MINEX04 testing will evaluate the use of each vendor's propietary minutiae template for fingerprint matching. The propietary template testing in MINEX04 uses the same format as this SDK testing but will include more vendors.

\section{Testing Strategy}

The results in this report are based on a very simple strategy of summing the matcher scores obtained for the right and left index fingers into a single score. This score is used to evaluate the matching accuracy for two fingers. This test did not search for the best strategy for combining the index finger scores. The intent of this report is to show what can be achieved from a simple two finger matching strategy.

Previous SDK testing used sample sizes of 6,000 subjects and computed a complete score matrix using the first capture as the probe and the second as the gallery. This produced 6,000 mate scores and 35,994,000 non-mate scores. This match distribution sample size works for single finger matchers but was not large enough when using two finger matching. The non-match distribution size is hundreds of times larger than these tests require.

For the two finger matcher test, the sample size used for each dataset tested was approximately 60,000 mates and 120,000 true non-mates, these sizes varied slightly as consolidations were made. The tests were setup so that the gallery images were the second instances of the 60,000 mates. The non-mate scores were obtained by matching the first 60,000 non-mates probes against the 60,000 mate gallery and then repeating this for the next 60,000 non-mates probes.

The larger sample size created problems with the previous test strategy of extracting all the templates into memory and matching from memory. There was not enough memory on the machines to store all 240,000 templates. The NIST software that accessed the SDK libraries was redesigned to do matching in two steps. First, the templates were 
extracted for each image written to disk. The templates are randomly read in pairs and scores computed for each pair of templates. The resulting scores are then stored on disk.

\section{Evaluation Data}

Since the current scope of this report is supporting NIST work for HSPD-11 and HSPD-12 the only datasets being used for the current testing is from single finger livescan capture devices. The data is from several sources: US VISIT Port of Entry (POE) and Bio-Visa Application (BVA), Department of State (DOS), and Department of Homeland Security (DHS2). At this time only the DOS data sample has been completely consolidated by human examiners.

The data used for testing (60,000 mates and 120,000 non-mates) was randomly selected from the available data for each dataset.

\section{DHS 2-Finger Images (DHS2)}

\section{Description}

DHS recidivist cases, the majority of which are border crossing cases with Mexico.

Environment: border patrol field operations

\begin{tabular}{|l|l|}
\hline Number of Subjects & Instances per Subject \\
& $\begin{array}{l}\text { Minimum of } 2 \text { cases per person, } \\
\text { where each case contains one right } \\
\text { index impression and one left index } \\
\text { impression. }\end{array}$ \\
\hline Impression Type $\sim 632,000)$ & Finger Positions Captured \\
Live-scan Plain & Right and Left Index \\
\hline Capture Device(s) & Availability \\
& Government use only \\
\hline
\end{tabular}

\section{Data Preparation}

The sample of data used for this two finger SDK testing has not been consolidated by human examiners.

\footnotetext{
${ }^{1}$ Specific hardware and software products identified in this report do not imply recommendation or endorsement by the National Institute of Standards and Technology.
} 


\section{Department of State Mexican Visa Database (DOS)}

\section{Description}

DOS Mexican Visa cases

Environment: Mexican Consulates offices

\begin{tabular}{|l|l|}
\hline Number of Subjects & $\begin{array}{l}\text { Instances per Subject } \\
\text { Minimum of } 2 \text { cases per person, } \\
\text { where each case contains one right } \\
\text { index impression and one left index } \\
\text { impression. }\end{array}$ \\
\hline Live-scan Plain & Finger Positions Captured \\
\hline Capture Device(s) & Right and Left Index \\
Identix DFR-90 & Availability \\
& Government use only \\
\hline Data Preparation Type & \\
\hline
\end{tabular}

\section{Data Preparation}

The sample of data used for this two finger SDK testing has been consolidated by human examiners. 


\section{U.S. VISIT Point of Entry Data (POE) and Bio-Visa Application (BVA)}

Description

Data from U.S. VISIT captured from persons entering the U.S. at airport points of entry (POE) and at Consulates when applying for a U.S. VISA (BVA).

\begin{tabular}{|c|c|}
\hline Number of Subjects & Instances per Subject \\
\hline $\begin{array}{l}\sim 3.5 \text { Million with one POE instance } \\
\sim 715 \mathrm{~K} \text { with } 2 \text { or more POE instances } \\
\sim 290 \mathrm{~K} \text { with POE and BVA instances }\end{array}$ & $\begin{array}{l}\text { One to many cases per person, with } \\
\text { each case containing one right index } \\
\text { finger impression and one left index } \\
\text { finger impression. }\end{array}$ \\
\hline Impression Type & Finger Positions Captured \\
\hline Live-scan Plain & Right and Left Index \\
\hline Capture Device(s) & Availability \\
\hline $\begin{array}{l}\text { Cross Match 300A (POE) } \\
\text { Smiths-Heimann ACC01394 (BVA) }\end{array}$ & Government use only \\
\hline Data Preparation & \\
\hline
\end{tabular}

consolidated by human examiners. 


\section{Results}

The 60,000 match scores were used to generate match distributions for each matcher and dataset combination. The 120,000 nonmatch scores were used to generate nonmatch distributions for each of the corresponding matcher and dataset combinations. These two distributions were then used to generate sets of ROC (Receiver Operator Curve) and DET (Detection Error Tradeoff) curves. These sample sizes were selected to provide accurate FAR calculations down to 0.0001 .

The number of ROC and DET curves was too large to put in the body of this report so they are included in appendices. Appendix A contains the ROC/DET curves for each SDK tested. Appendix B contains the ROC/DET curves for each dataset.

Tables 1 and 2 show TARs achieved at FARs of 0.0001 and 0.01 for each SDK in alphabetical order. Tables 3 and 4 show the same information using FRR instead of TAR. The highest TAR value for each dataset at FAR of 0.0001 is 0.9881 (DHS2, D), 0.9983 (DOS, R), 0.9986 (POE, H,I\&R), and 0.9987 (POEBVA, H,I\&R). At FAR 0.01 the highest TAR value is 0.9982 (DHS2, D), 0.9996 (DOS, H,I\&R), 0.999 (POE, H,I,O\&R), and 0.9995 (POEBVA, H,I\&R). These are significantly better than the same points for single fingers shown in table 5. Clearly using two fingers helps all vendors achieve higher TARs at a fixed FAR point. Two fingers can make a lower scoring single finger vendor (K for DHS2 RI-0.871 and LI-0.8769) more competitive with other vendors (K for DHS2 0.9661).

Tables 6 and 7 show the FAR values at a set TAR of 0.995 and 0.998 . These points show some separation in the different vendor SDKs when achieving a high level of TAR performance. The lowest FAR value for each dataset at a TAR of 0.998 is 0.0081 (DHS2, D), 0.0001 (DOS, R), <0.00002 (POE, H,I,O\&R), and <0.00002 (POEBVA, H,I\&R). Although two fingers helped improve K's TAR (0.9661) performance at FAR 0.0001 at higher TAR (0.998) values the FAR increases significantly (0.4084).

Table 8 shows the equal error rate (EER) points for all the SDKs. This is another point to help separate the performance of each SDK. The lower the EER value is the better overall performance you will get from the matcher. The best equal error rate is 0.0008 for marcher H\&R on POEBVA and R on DOS matches. It is interesting to note that for this matcher the equal error rate for DHS2 data is 0.0087 an order of magnitude higher. The best equal error rate for DHS2 data is 0.0034 for matcher D. Most of the equal error rates for the other three data sets are in the 0.001 to 0.002 range.

Table 9 gives the vendor names that go with each SDK letter, showing that some vendors submitted multiple SDKs for testing. 


\begin{tabular}{|c|c|c|c|c|}
\hline & DHS2 & DOS & POE & POEBVA \\
\hline $\mathbf{D}$ & 0.9881 & 0.9845 & 0.9946 & 0.9905 \\
\hline $\mathbf{F}$ & 0.9851 & 0.9944 & 0.9971 & 0.9969 \\
\hline $\mathbf{H}$ & 0.9833 & 0.9978 & 0.9986 & 0.9987 \\
\hline $\mathbf{I}$ & 0.9865 & 0.9978 & 0.9985 & 0.9986 \\
\hline $\mathbf{J}$ & & 0.9909 & 0.9965 & 0.9957 \\
\hline $\mathbf{K}$ & 0.9661 & 0.9808 & 0.9911 & 0.9909 \\
\hline $\mathbf{O}$ & 0.9820 & 0.9969 & 0.9984 & 0.9981 \\
\hline $\mathbf{P}$ & 0.9779 & 0.9948 & 0.9978 & 0.9971 \\
\hline $\mathbf{Q}$ & 0.9834 & 0.9960 & 0.9968 & 0.9955 \\
\hline $\mathbf{R}$ & & 0.9983 & 0.9987 & 0.9987 \\
\hline
\end{tabular}

Table 1: TAR at a FAR of 0.0001

\begin{tabular}{|c|c|c|c|c|}
\hline & DHS2 & DOS & POE & POEBVA \\
\hline $\mathbf{D}$ & 0.9982 & 0.9950 & 0.9981 & 0.9982 \\
\hline $\mathbf{F}$ & 0.9949 & 0.9985 & 0.9988 & 0.9992 \\
\hline $\mathbf{H}$ & 0.9916 & 0.9996 & 0.9990 & 0.9995 \\
\hline $\mathbf{I}$ & 0.9976 & 0.9996 & 0.9990 & 0.9994 \\
\hline $\mathbf{J}$ & & 0.9966 & 0.9983 & 0.9981 \\
\hline $\mathbf{K}$ & 0.9885 & 0.9933 & 0.9969 & 0.9966 \\
\hline $\mathbf{O}$ & 0.9892 & 0.9989 & 0.9989 & 0.9990 \\
\hline $\mathbf{P}$ & 0.9837 & 0.9973 & 0.9984 & 0.9980 \\
\hline $\mathbf{Q}$ & $\mathrm{NA}$ & $\mathrm{NA}$ & $\mathrm{NA}$ & $\mathrm{NA}$ \\
\hline $\mathbf{R}$ & & 0.9997 & 0.9990 & 0.9996 \\
\hline
\end{tabular}

Table 2: TAR at a FAR of 0.01

\begin{tabular}{|c|c|c|c|c|}
\hline & DHS2 & DOS & POE & POEBVA \\
\hline $\mathbf{D}$ & 0.0119 & 0.0155 & 0.0054 & 0.0095 \\
\hline $\mathbf{F}$ & 0.0149 & 0.0056 & 0.0029 & 0.0031 \\
\hline $\mathbf{H}$ & 0.0167 & 0.0022 & 0.0014 & 0.0013 \\
\hline $\mathbf{I}$ & 0.0135 & 0.0022 & 0.0015 & 0.0014 \\
\hline $\mathbf{J}$ & & 0.0091 & 0.0035 & 0.0043 \\
\hline $\mathbf{K}$ & 0.0339 & 0.0192 & 0.0089 & 0.0091 \\
\hline $\mathbf{O}$ & 0.0180 & 0.0031 & 0.0016 & 0.0019 \\
\hline $\mathbf{P}$ & 0.0221 & 0.0052 & 0.0022 & 0.0029 \\
\hline $\mathbf{Q}$ & 0.0166 & 0.0040 & 0.0032 & 0.0045 \\
\hline $\mathbf{R}$ & & 0.0017 & 0.0013 & 0.0013 \\
\hline
\end{tabular}

Table 3: FRR at a FAR of 0.0001 


\begin{tabular}{|c|c|c|c|c|}
\hline & DHS2 & DOS & POE & POEBVA \\
\hline $\mathbf{D}$ & 0.0018 & 0.0050 & 0.0019 & 0.0018 \\
\hline $\mathbf{F}$ & 0.0051 & 0.0015 & 0.0012 & 0.0008 \\
\hline $\mathbf{H}$ & 0.0084 & 0.0004 & 0.0010 & 0.0005 \\
\hline $\mathbf{I}$ & 0.0024 & 0.0004 & 0.0010 & 0.0006 \\
\hline $\mathbf{J}$ & & 0.0034 & 0.0017 & 0.0019 \\
\hline $\mathbf{K}$ & 0.0115 & 0.0067 & 0.0031 & 0.0034 \\
\hline $\mathbf{O}$ & 0.0108 & 0.0011 & 0.0011 & 0.0010 \\
\hline $\mathbf{P}$ & 0.0163 & 0.0027 & 0.0016 & 0.0020 \\
\hline $\mathbf{Q}$ & NA & NA & NA & NA \\
\hline $\mathbf{R}$ & & 0.0003 & 0.0010 & 0.0004 \\
\hline
\end{tabular}

Table 4: FRR at a FAR of 0.01

\begin{tabular}{|c|c|c|c|c|c|c|c|c|}
\hline & \multicolumn{2}{|c|}{ DHS2 } & \multicolumn{2}{c|}{ DOS } & \multicolumn{2}{c|}{ POE } & \multicolumn{2}{c|}{ POEBVA } \\
\hline & RI & LI & RI & LI & RI & LI & RI & LI \\
\hline $\mathbf{D}$ & 0.9407 & 0.9468 & 0.9626 & 0.9320 & 0.9727 & 0.9588 & 0.9715 & 0.9486 \\
\hline $\mathbf{F}$ & 0.9570 & 0.9578 & 0.9763 & 0.9567 & 0.9805 & 0.9675 & 0.9804 & 0.9626 \\
\hline $\mathbf{H}$ & 0.9555 & 0.9554 & 0.9915 & 0.9759 & 0.9896 & 0.9854 & 0.9918 & 0.9815 \\
\hline $\mathbf{I}$ & 0.9645 & 0.9676 & 0.9888 & 0.9762 & 0.9867 & 0.9814 & 0.9887 & 0.9774 \\
\hline $\mathbf{J}$ & & & 0.9664 & 0.9405 & 0.9711 & 0.9592 & 0.9740 & 0.9548 \\
\hline $\mathbf{K}$ & 0.8710 & 0.8769 & 0.9390 & 0.8909 & 0.9490 & 0.9282 & 0.9464 & 0.9174 \\
\hline $\mathbf{O}$ & 0.9540 & 0.9530 & 0.9879 & 0.9713 & 0.9873 & 0.9830 & 0.9894 & 0.9764 \\
\hline $\mathbf{P}$ & 0.9410 & 0.9387 & 0.9807 & 0.9587 & 0.9815 & 0.9735 & 0.9838 & 0.9675 \\
\hline $\mathbf{Q}$ & 0.9471 & 0.9555 & 0.9845 & 0.9740 & 0.9760 & 0.9707 & 0.9823 & 0.9650 \\
\hline $\mathbf{R}$ & & & 0.9916 & 0.9783 & 0.9898 & 0.9860 & 0.9910 & 0.9821 \\
\hline
\end{tabular}

Table 5: Single finger TAR at a FAR of 0.0001

\begin{tabular}{|c|c|c|c|c|c|c|c|c|}
\hline & \multicolumn{2}{|c|}{ DHS2 } & \multicolumn{2}{c|}{ DOS } & \multicolumn{2}{c|}{ POE } & \multicolumn{2}{c|}{ POEBVA } \\
\hline & RI & LI & RI & LI & RI & LI & RI & LI \\
\hline $\mathbf{D}$ & 0.0593 & 0.0532 & 0.0374 & 0.0680 & 0.0273 & 0.0412 & 0.0285 & 0.0514 \\
\hline $\mathbf{F}$ & 0.0430 & 0.0422 & 0.0237 & 0.0433 & 0.0195 & 0.0325 & 0.0196 & 0.0374 \\
\hline $\mathbf{H}$ & 0.0445 & 0.0446 & 0.0085 & 0.0241 & 0.0104 & 0.0146 & 0.0082 & 0.0185 \\
\hline $\mathbf{I}$ & 0.0355 & 0.0324 & 0.0112 & 0.0238 & 0.0133 & 0.0186 & 0.0113 & 0.0226 \\
\hline $\mathbf{J}$ & & & 0.0336 & 0.0595 & 0.0289 & 0.0408 & 0.0260 & 0.0452 \\
\hline $\mathbf{K}$ & 0.1290 & 0.1231 & 0.0610 & 0.1091 & 0.0510 & 0.0718 & 0.0536 & 0.0826 \\
\hline $\mathbf{O}$ & 0.0460 & 0.0470 & 0.0121 & 0.0287 & 0.0127 & 0.0170 & 0.0106 & 0.0236 \\
\hline $\mathbf{P}$ & 0.0590 & 0.0613 & 0.0193 & 0.0413 & 0.0185 & 0.0265 & 0.0162 & 0.0325 \\
\hline $\mathbf{Q}$ & 0.0529 & 0.0445 & 0.0155 & 0.0260 & 0.0240 & 0.0293 & 0.0177 & 0.0350 \\
\hline $\mathbf{R}$ & & & 0.0084 & 0.0217 & 0.0102 & 0.0140 & 0.0090 & 0.0179 \\
\hline
\end{tabular}

Table 6: Single finger FRR at a FAR of 0.0001 


\begin{tabular}{|c|c|c|c|c|}
\hline & DHS2 & DOS & POE & POEBVA \\
\hline $\mathbf{D}$ & 0.0015 & 0.0099 & 0.0002 & 0.0004 \\
\hline $\mathbf{F}$ & 0.0104 & 0.0001 & $<0.00002$ & $<0.00002$ \\
\hline $\mathbf{H}$ & 0.0524 & $<0.00002$ & $<0.00002$ & $<0.00002$ \\
\hline $\mathbf{I}$ & 0.0040 & $<0.00002$ & $<0.00002$ & $<0.00002$ \\
\hline $\mathbf{J}$ & & 0.0020 & $<0.00002$ & $<0.00002$ \\
\hline $\mathbf{K}$ & 0.0860 & 0.0260 & 0.0012 & 0.0023 \\
\hline $\mathbf{O}$ & NA & $<0.00002$ & $<0.00002$ & $<0.00002$ \\
\hline $\mathbf{P}$ & NA & 0.0001 & $<0.00002$ & $<0.00002$ \\
\hline $\mathbf{Q}$ & NA & $<0.00002$ & $<0.00002$ & 0.0001 \\
\hline $\mathbf{R}$ & & $<0.00002$ & $<0.00002$ & $<0.00002$ \\
\hline
\end{tabular}

Table 7: FAR at a TAR of 0.995

\begin{tabular}{|c|c|c|c|c|}
\hline & DHS2 & DOS & POE & POEBVA \\
\hline $\mathbf{D}$ & 0.0081 & 0.0967 & 0.0080 & 0.0075 \\
\hline $\mathbf{F}$ & 0.0295 & 0.0057 & 0.0004 & 0.0007 \\
\hline $\mathbf{H}$ & NA & 0.0002 & $<0.00002$ & $<0.00002$ \\
\hline $\mathbf{I}$ & 0.0127 & 0.0002 & $<0.00002$ & $<0.00002$ \\
\hline $\mathbf{J}$ & & 0.0623 & 0.0040 & 0.0079 \\
\hline $\mathbf{K}$ & 0.4084 & 0.2144 & 0.0588 & 0.0621 \\
\hline $\mathbf{O}$ & NA & 0.0009 & $<0.00002$ & 0.0001 \\
\hline $\mathbf{P}$ & NA & NA & 0.0004 & 0.009 \\
\hline $\mathbf{Q}$ & NA & NA & 0.0014 & NA \\
\hline $\mathbf{R}$ & & 0.0001 & $<0.00002$ & $<0.00002$ \\
\hline
\end{tabular}

Table 8: FAR at a TAR of 0.998

\begin{tabular}{|c|c|c|c|c|}
\hline & DHS2 & DOS & POE & POEBVA \\
\hline $\mathbf{D}$ & 0.0034 & 0.0058 & 0.0026 & 0.0029 \\
\hline $\mathbf{F}$ & 0.0067 & 0.0026 & 0.0016 & 0.0016 \\
\hline $\mathbf{H}$ & 0.0087 & 0.0011 & 0.0011 & 0.0008 \\
\hline $\mathbf{I}$ & 0.0046 & 0.0010 & 0.0012 & 0.0009 \\
\hline $\mathbf{J}$ & & 0.0042 & 0.0022 & 0.0024 \\
\hline $\mathbf{K}$ & 0.0111 & 0.0074 & 0.0038 & 0.0042 \\
\hline $\mathbf{O}$ & 0.0107 & 0.0018 & 0.0013 & 0.0013 \\
\hline $\mathbf{P}$ & 0.0159 & 0.0031 & 0.0018 & 0.0023 \\
\hline $\mathbf{Q}$ & 0.0101 & 0.0023 & 0.0019 & 0.0023 \\
\hline $\mathbf{R}$ & & 0.0008 & 0.0011 & 0.0008 \\
\hline
\end{tabular}

Table 9: Equal Error Rates 


\begin{tabular}{|c|c|}
\hline SDK & Vendor Name \\
\hline D, F, I, R & Cogent Systems, Inc. \\
\hline H, O, P & NEC \\
\hline J & SAGEM Morpho, Inc. \\
\hline K & Neurotechnologija \\
\hline Q & ID Solutions, Inc. \\
\hline
\end{tabular}

Table 10: Vendor Names.

\section{Conclusions}

Two finger matching is better than single finger (Tables 1 and 5). For a FAR of 0.0001 the best (RI-POEBVA) TAR is 0.9918 and for two fingers the equivalent TAR is 0.9987. This effect is even more pronounced for the less accurate matcher K. On DHS2 data the single RI TAR is 0.8710 and the two finger result is 0.9661 . In both cases the FRR is reduced by more than a factor of four.

A lower scoring single finger matcher can make significant improvements by using two fingers and be competitive with the better single finger matchers. On good quality POEBVA matches the K matcher has a TAR of 0.9909 at a FAR of 0.0001 . Only one matcher on POEBVA data has a higher single finger score, $\mathrm{H}$ with 0.9919.

In general, it appears that the higher performing single finger matchers will be better two finger matchers at extreme performance points (ie. TAR of 0.998). The performance patterns also show that as TARs approach 1.0 the use of additional fingers, even for the most accurate matchers, produces less improvement. 


\section{References}

[1] C. I. Watson, C. L. Wilson, K. Marshall, M. Indovina, R. Snelick, "Studies of One-toOne Fingerprint Matchers with Vendor SDK Matchers”, NIST IR 7221, April 2005. http://fingerprint.nist.gov/SDK

[2] http://www.whitehouse.gov/news/releases/2004/08/20040827-8.html

[3] http://csrc.nist.gov/piv-project

[4] Minutiae Exchange Test 2004. http://fingerprint.nist.gov/minex04

[5] "Summary of NIST Standards for Biometric Accuracy, Tamper Resistance, and Interoperability,” PDF document at http://www.itl.nist.gov/iaui/894.03/pact/pact.html (“NIST Appendix A” link), November 2002.

[6] Public Law 107-56 (USA PATRIOT ACT); $107^{\text {th }}$ United States Congress, Washington, D.C.; 26 October 2001

[7] Public Law 107-173 (Enhanced Border Security and Visa Entry Reform Act of 2002); $107^{\text {th }}$ United States Congress, Washington, D.C.; 14 May 2002

[8] C L Wilson, C I Watson, M D Garris, A Hicklin; "Studies of Fingerprint Matching Using the NIST Verification Test Bed (VTB)" NIST IR 7020; National Institute of Standards and Technology; Gaithersburg Maryland , 07 July 2003 at ftp://sequoyah.nist.gov/pub/nist_internal_reports/ir_7020.pdf

[9] Charles Wilson, R. Austin Hicklin, Harold Korves, Bradford Ulery, Melissa Zoepfl, Mike Bone, Patrick Grother, Ross Micheals, Steve Otto, and Craig Watson, "Fingerprint Vendor Technology Evaluation 2003,” DRAFT NIST IR, June 2004.

[10] Stephen S. Wood and Charles L. Wilson, "Studies of Plain-to-Rolled Fingerprint Matching Using the NIST Algorithmic Test Bed (ATB),” NIST IR 7112; National Institute of Standards \& Technology, Gaithersburg Maryland at ftp://sequoyah.nist.gov/pub/nist_internal_reports/ir_7112.pdf

[11] C. L. Wilson, M. D. Garris, and C. A. Watson ,"Matching Performance for the US-VISIT IDENT System Using Flat Fingerprints,” NIST IR 7110; National Institute of Standards \& Technology, Gaithersburg Maryland, May 2004, at ftp://sequoyah.nist.gov/pub/nist_internal_reports/ir_7110.pdf

[12] P. J. Phillips, P. Grother, R. J. Micheals, D. M. Blackburn, E. Tabassi, and M. Bone, “Face recognition vendor test 2002," NIST IR 6965, National Institute of Standards \& Technology, Gaithersburg Maryland, March 2003, results at http://www.itl.nist.gov/iaui/894.03/face/face.html

[13] Other related NIST fingerprint work may be viewed at http://fingerprint.nist.gov. 


\section{Appendix A: ROC/DET plots for each SDK.}
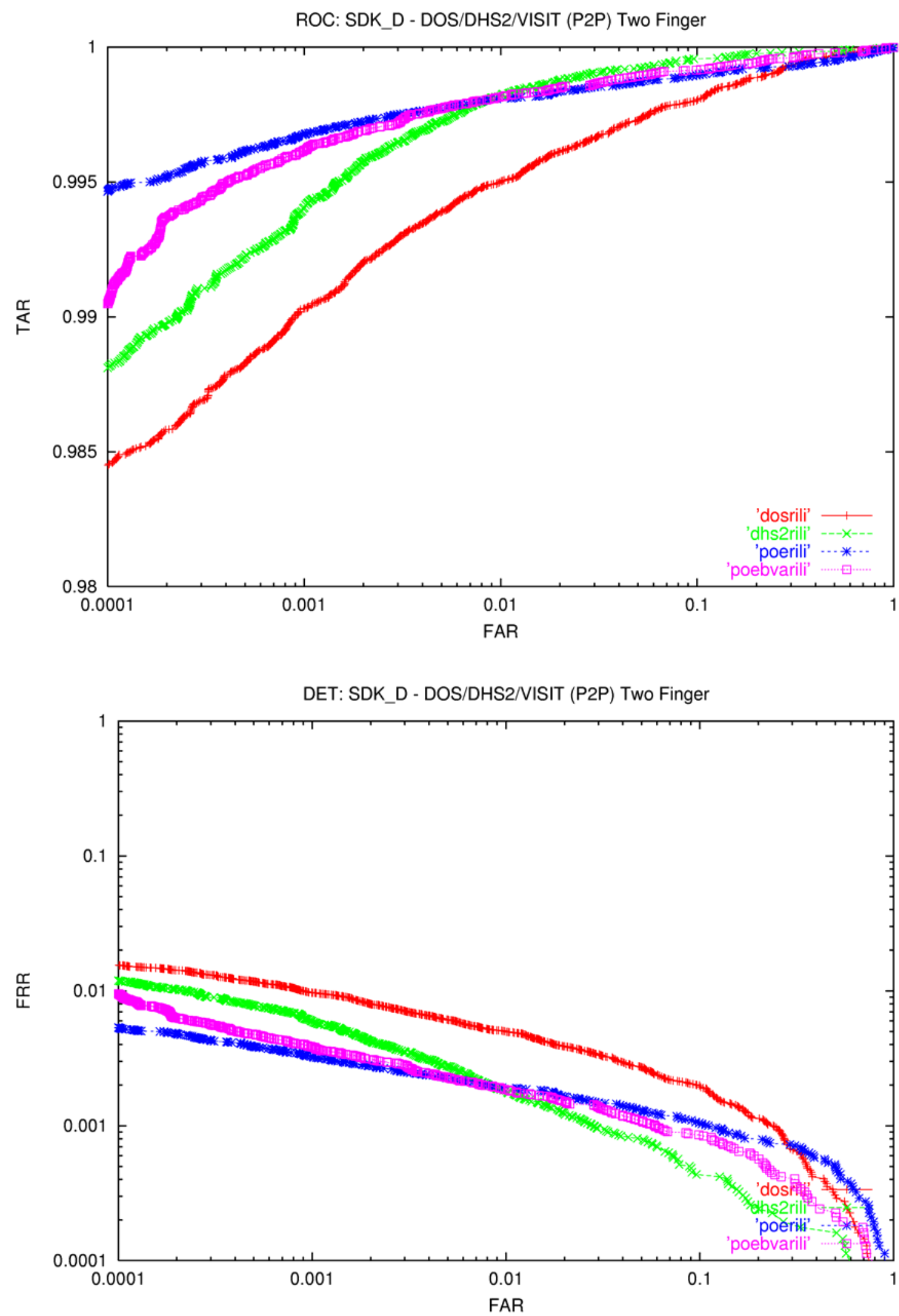

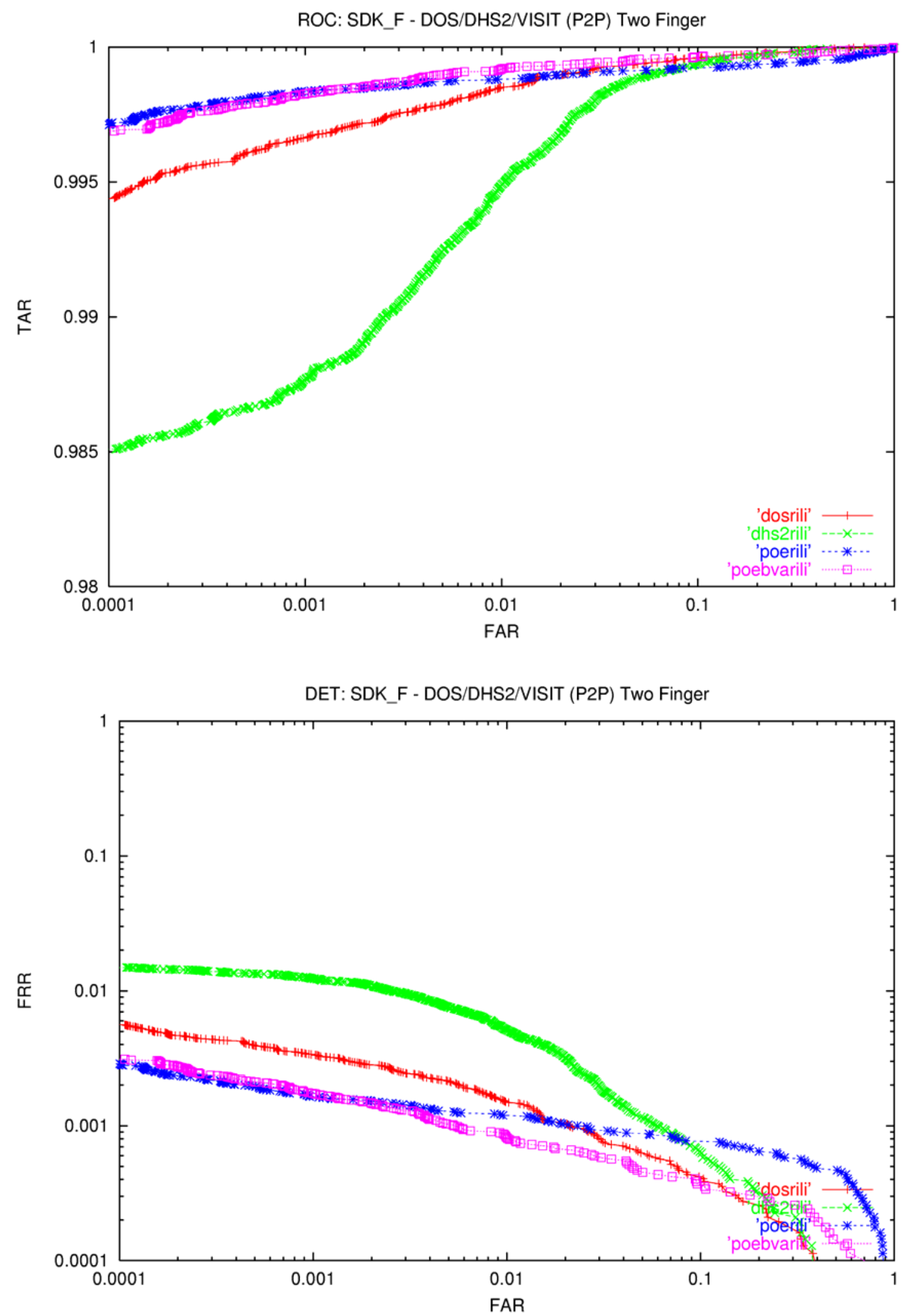

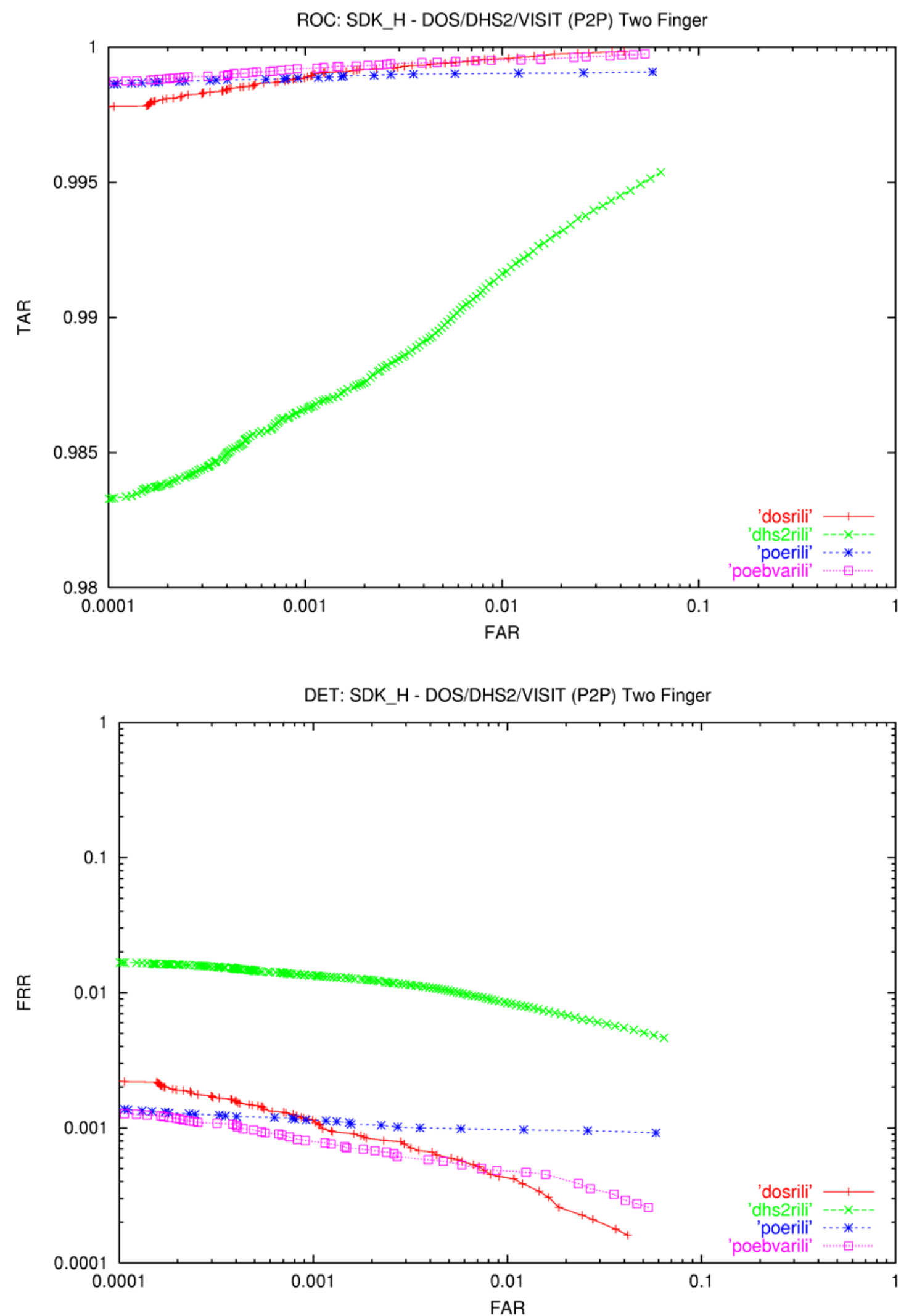

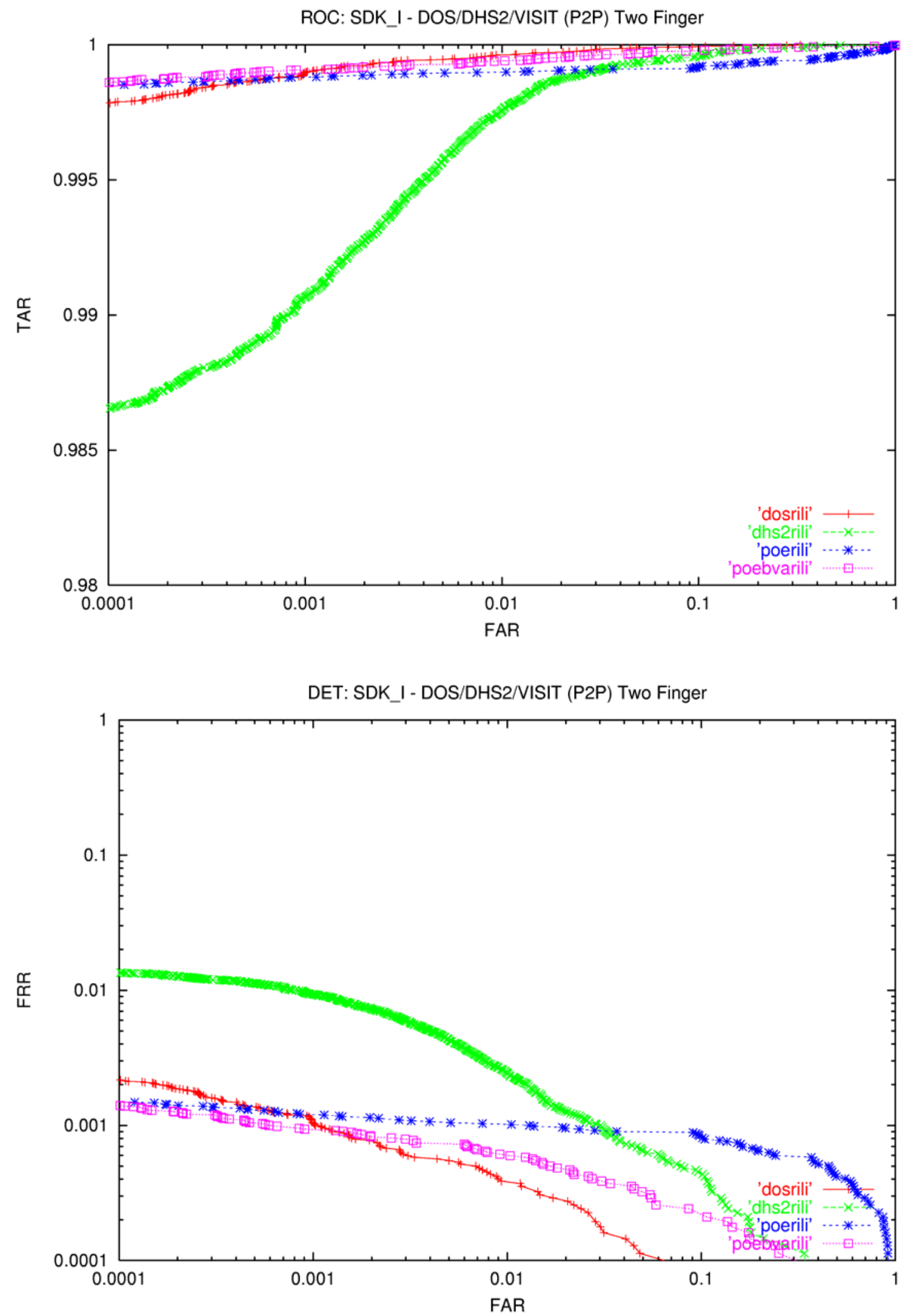

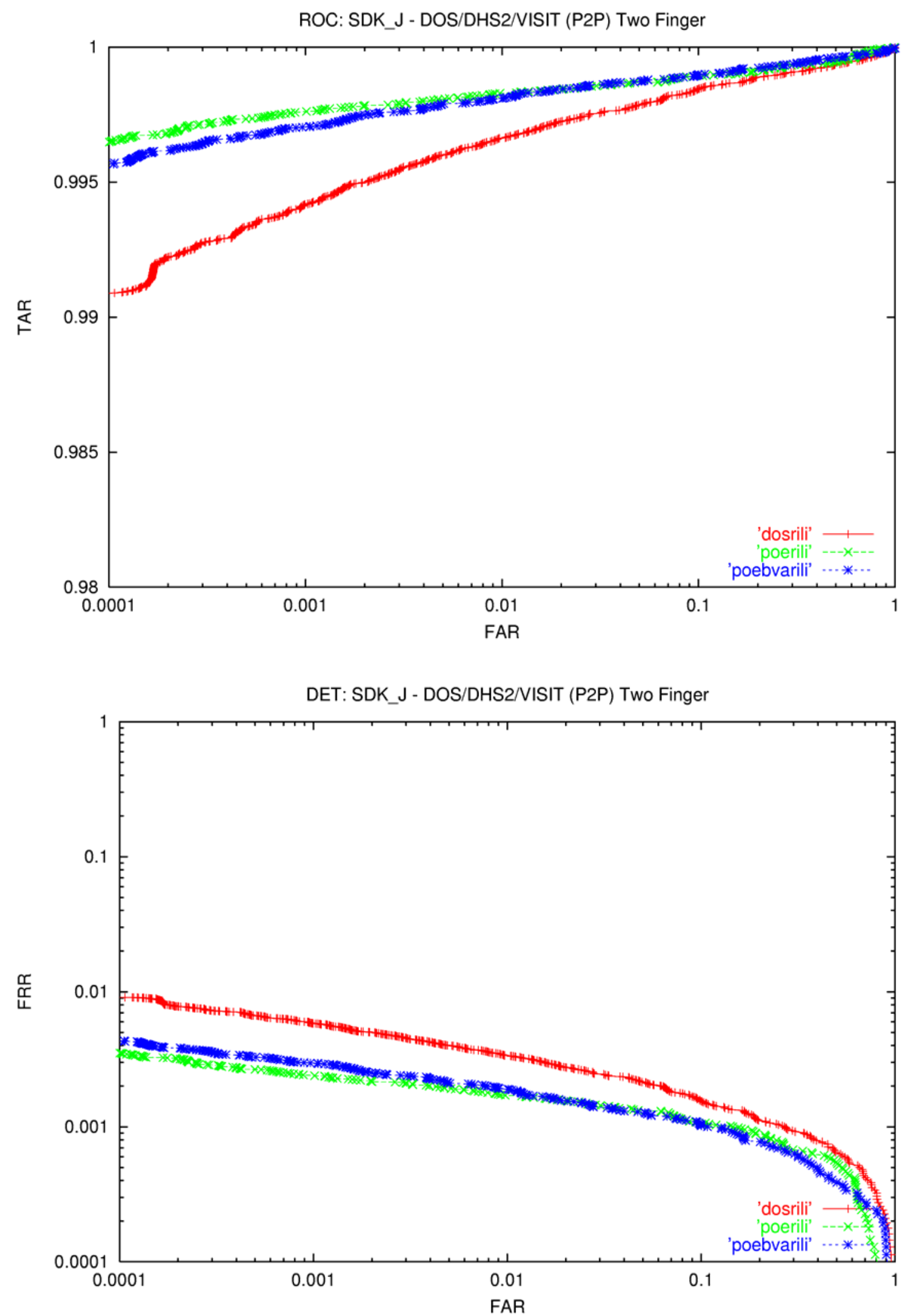

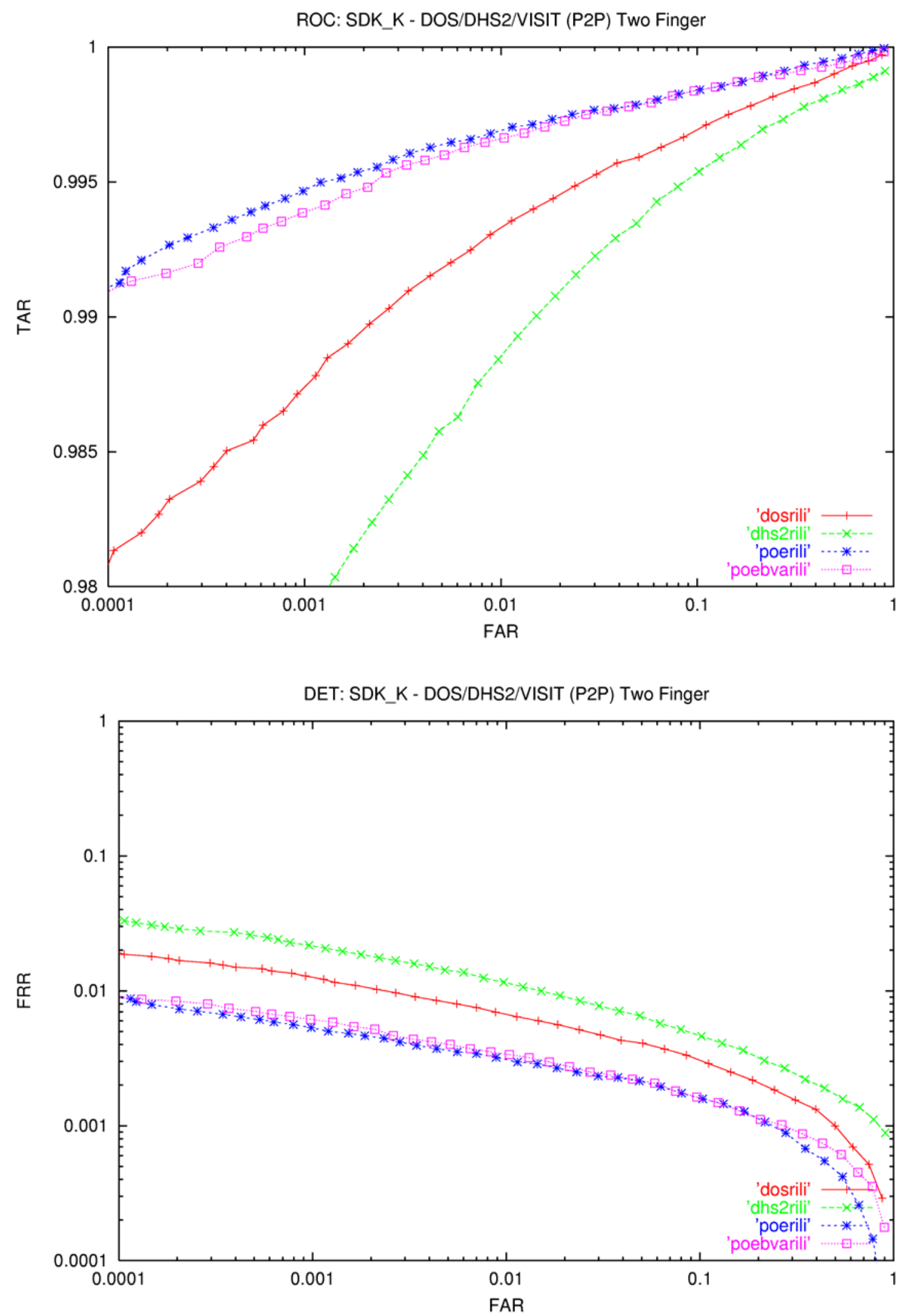

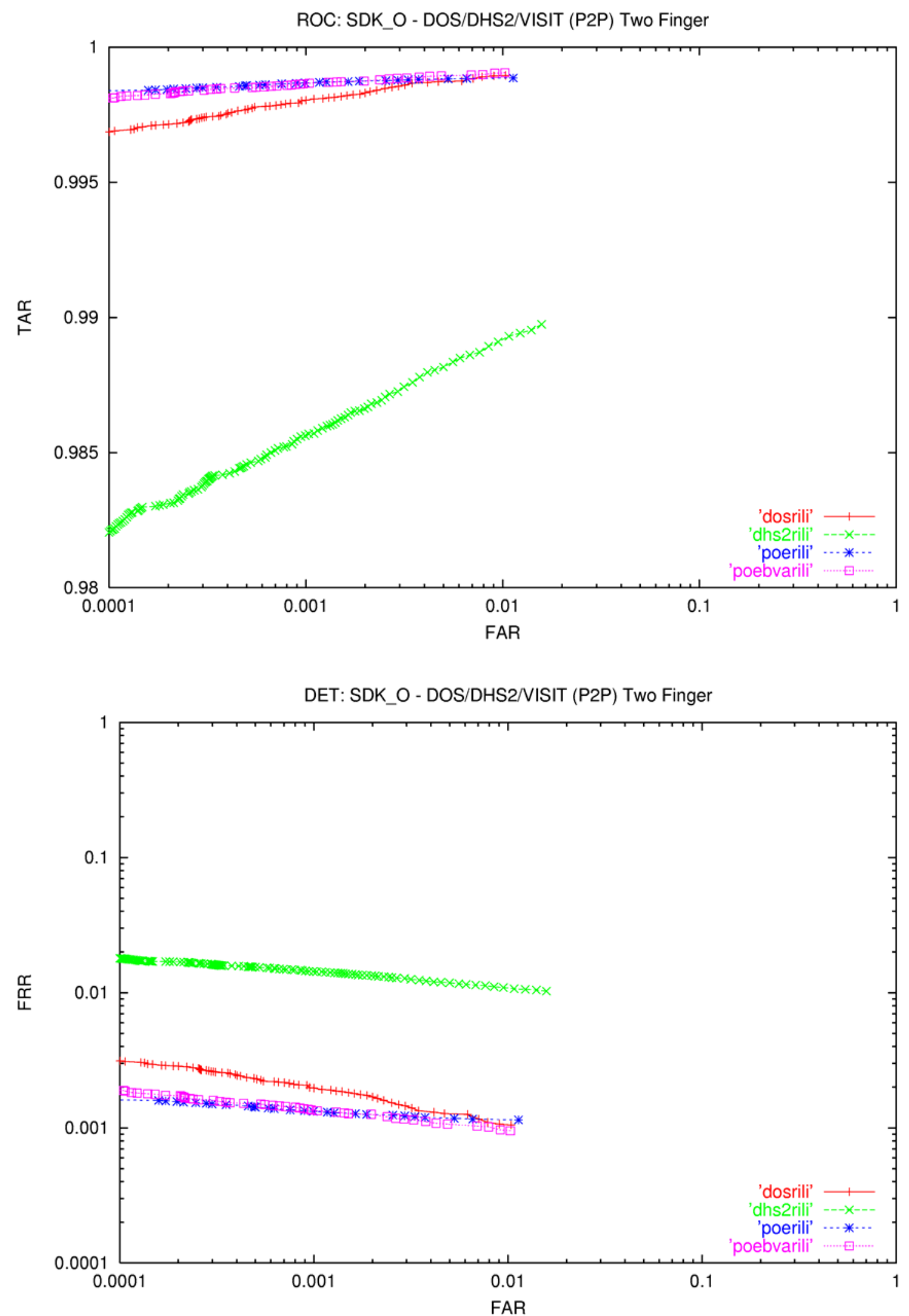

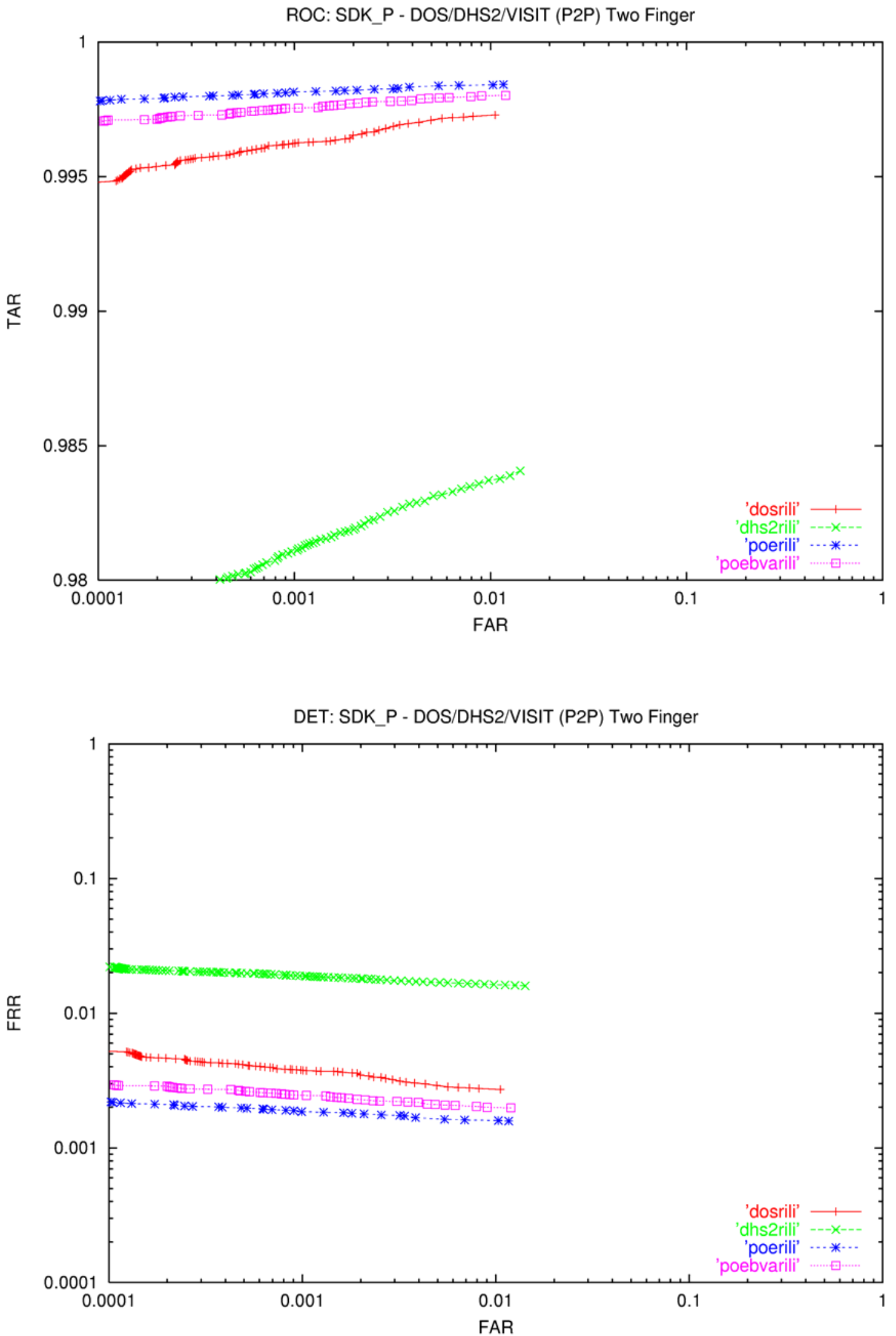

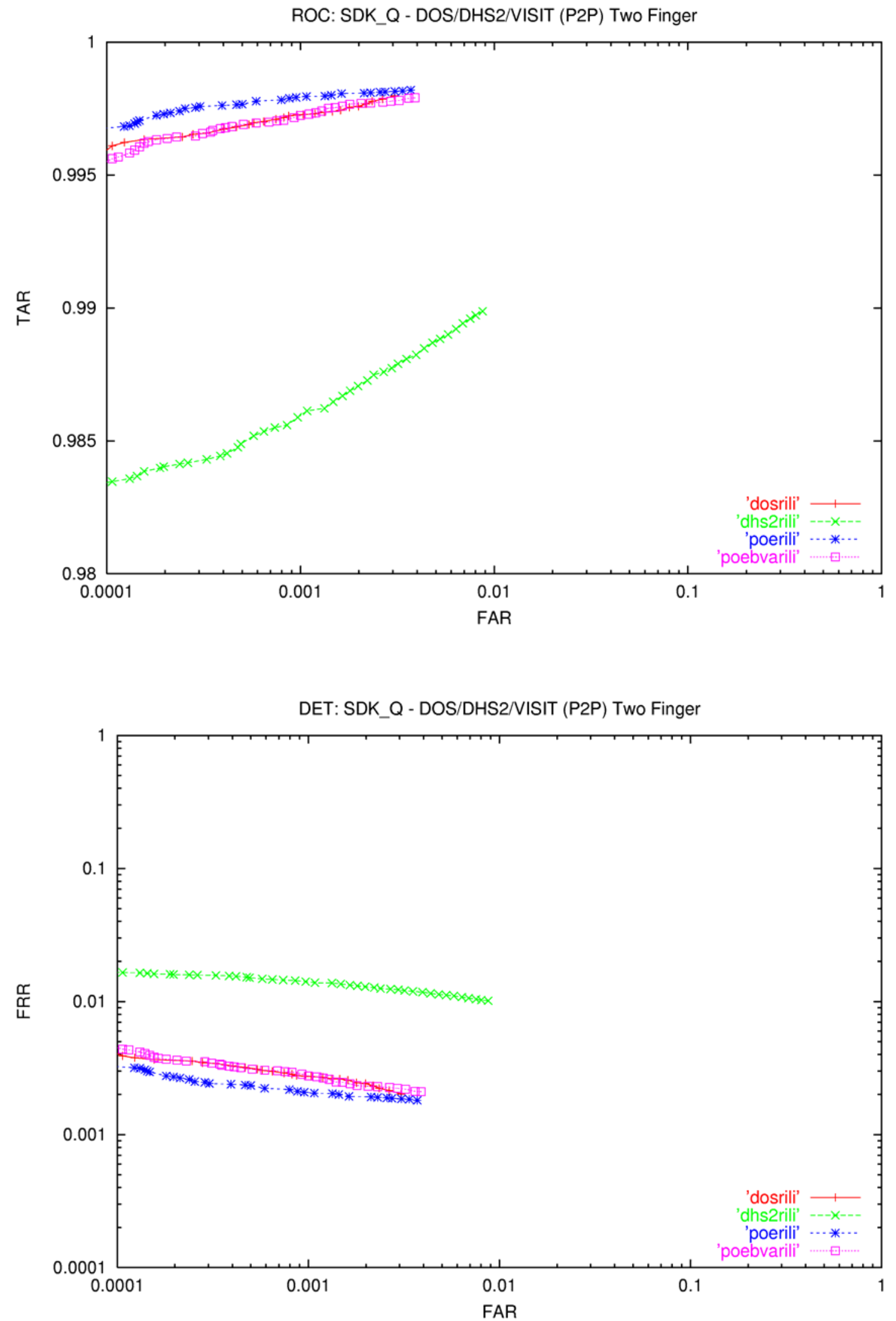

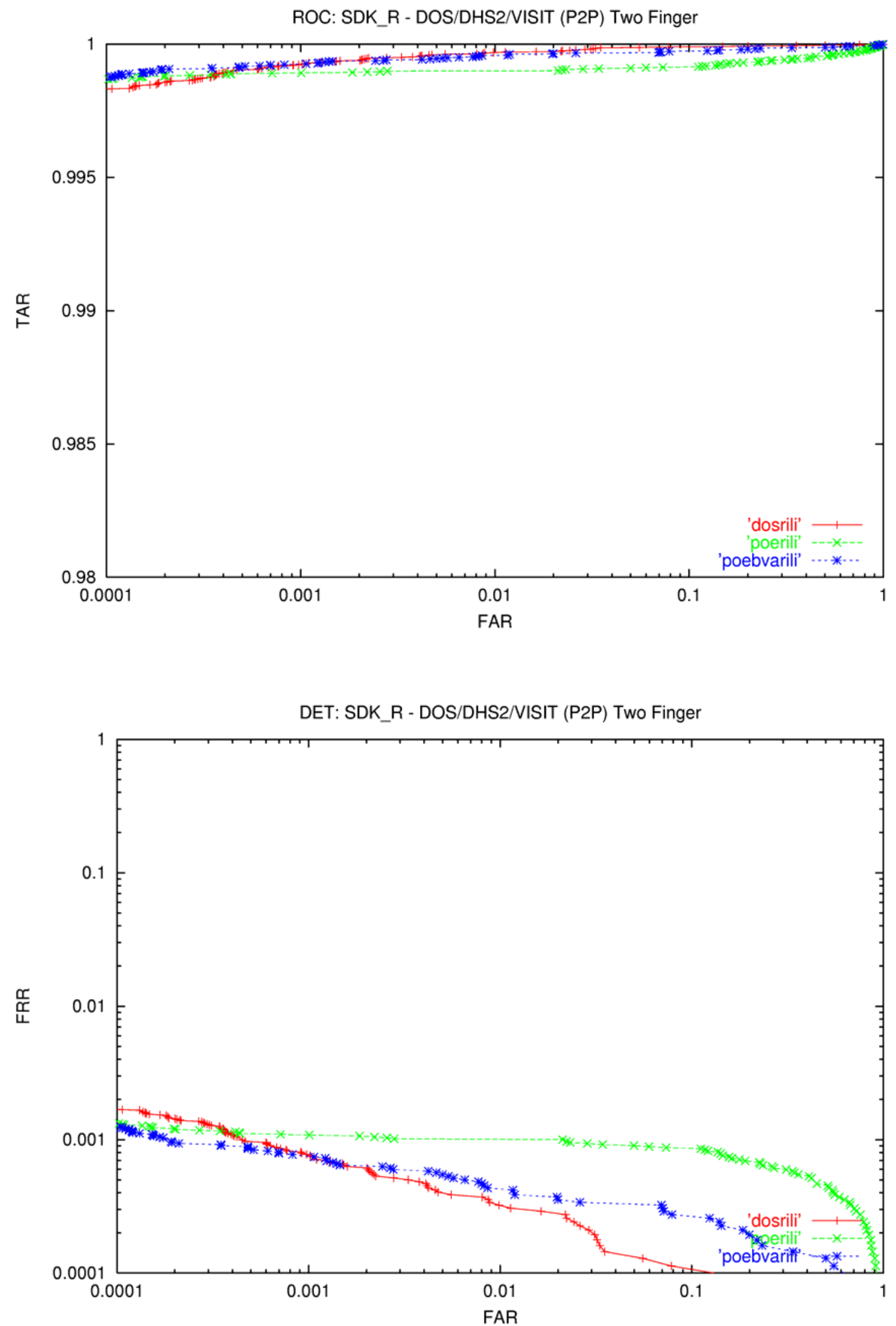


\section{Appendix B: ROC/DET plots for each Dataset.}
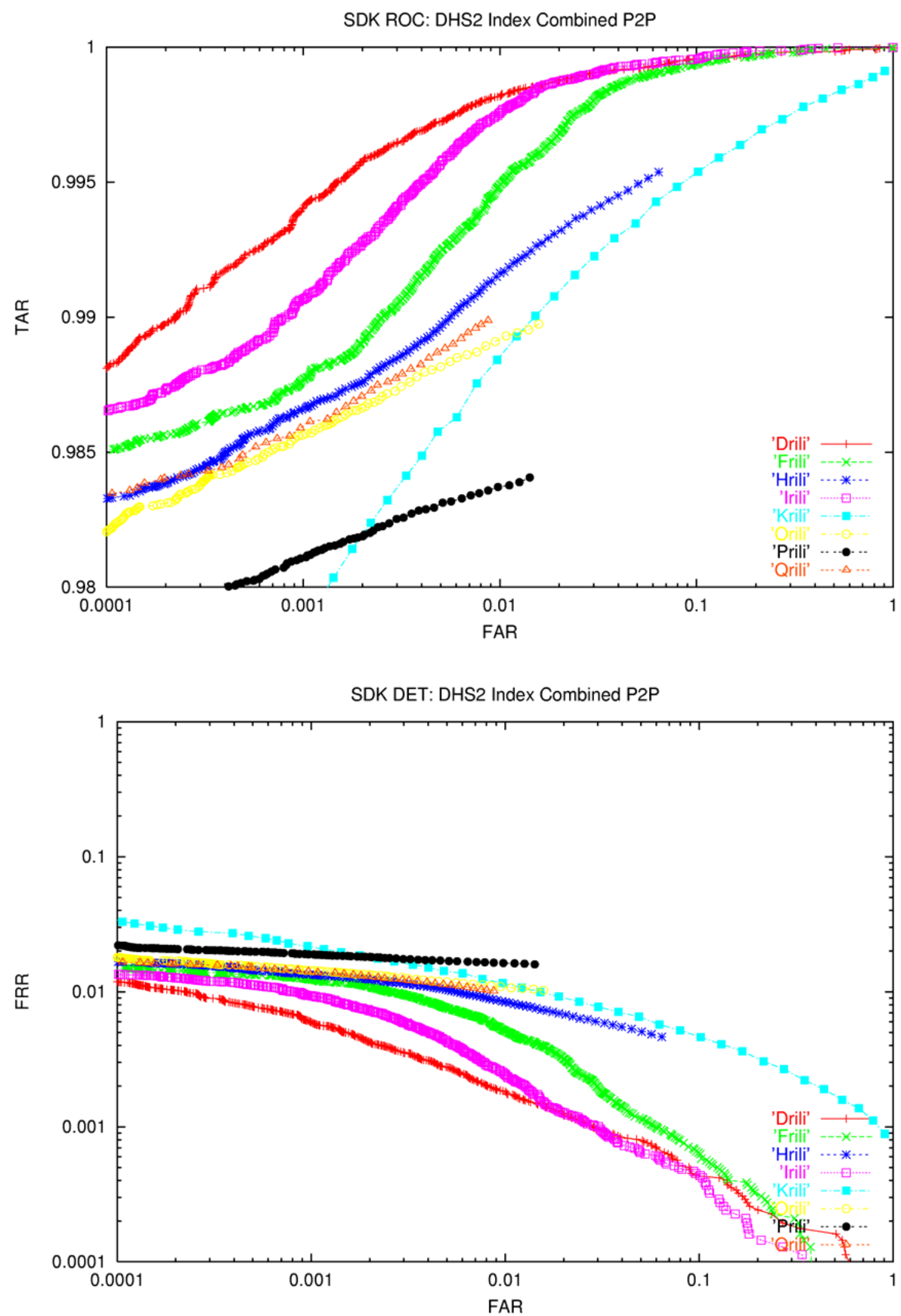

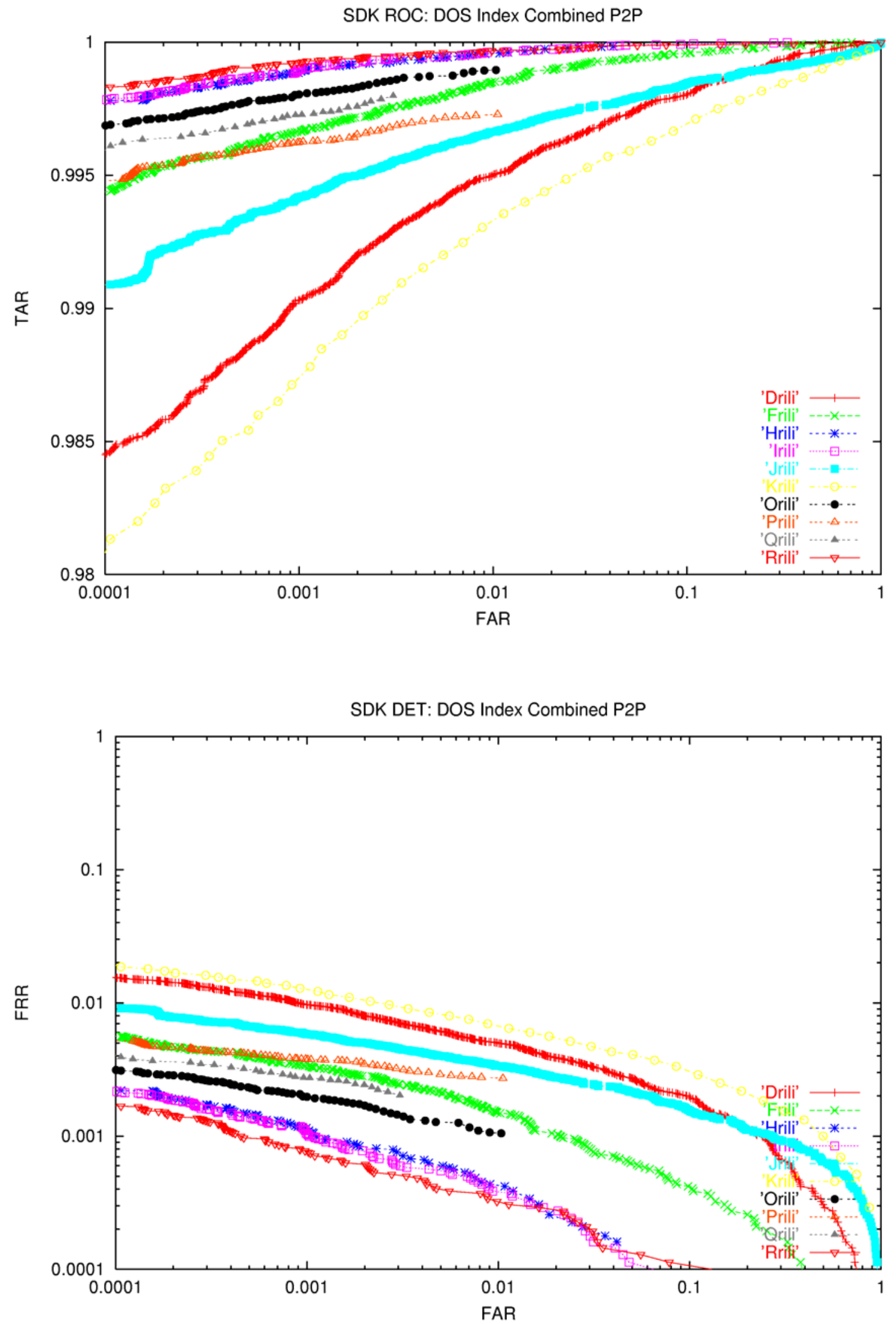


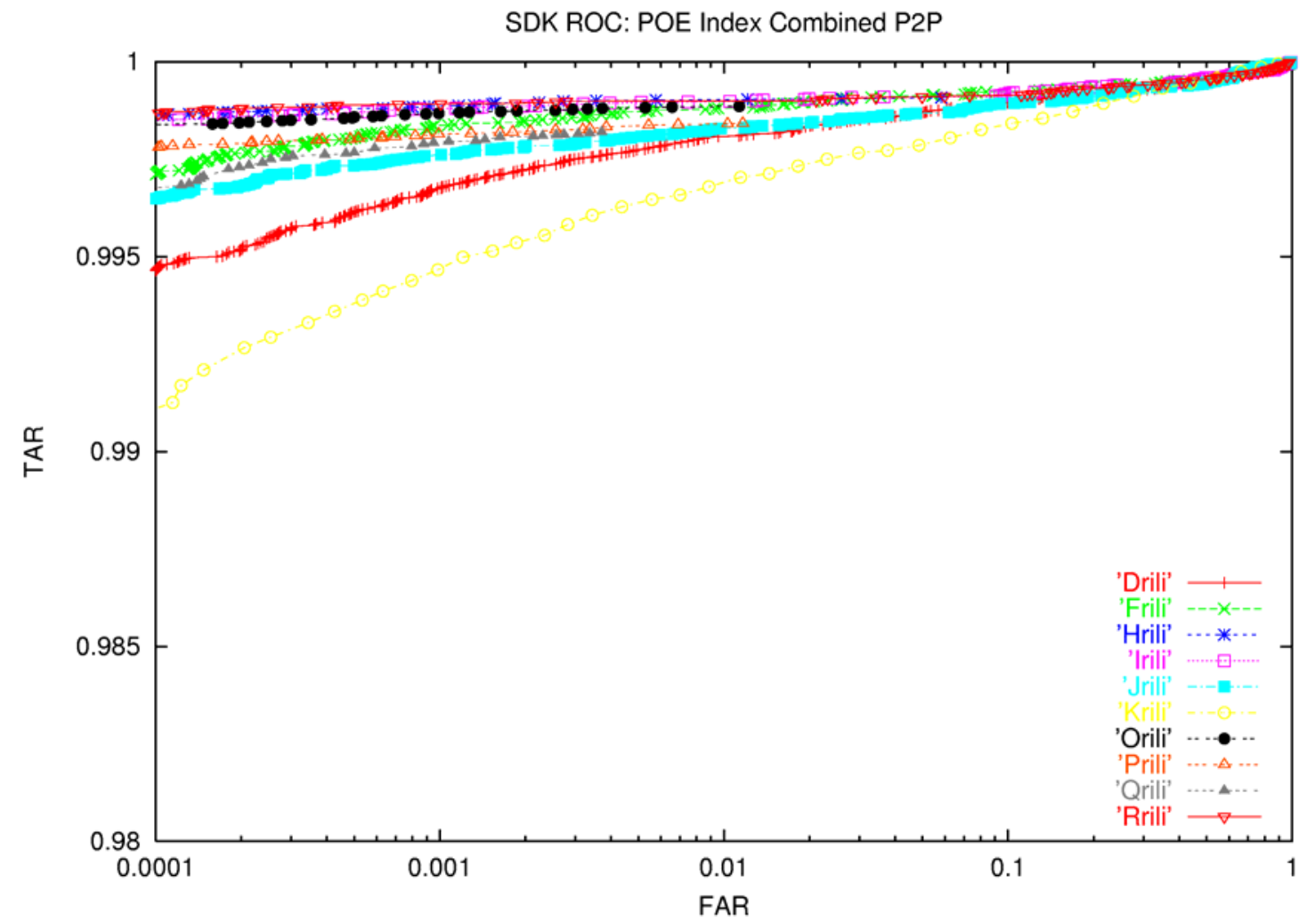

SDK DET: POE Index Combined P2P

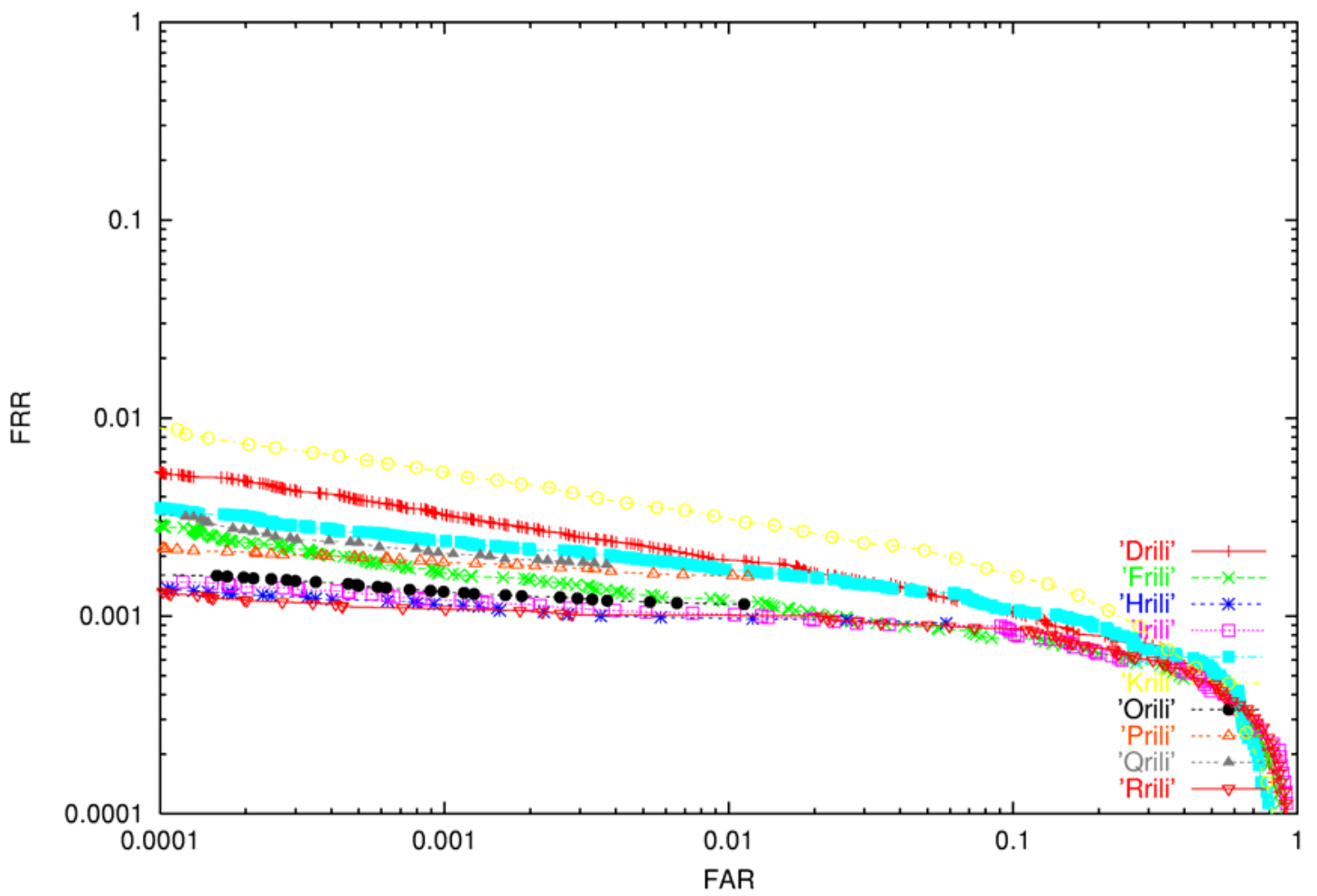

B-3 

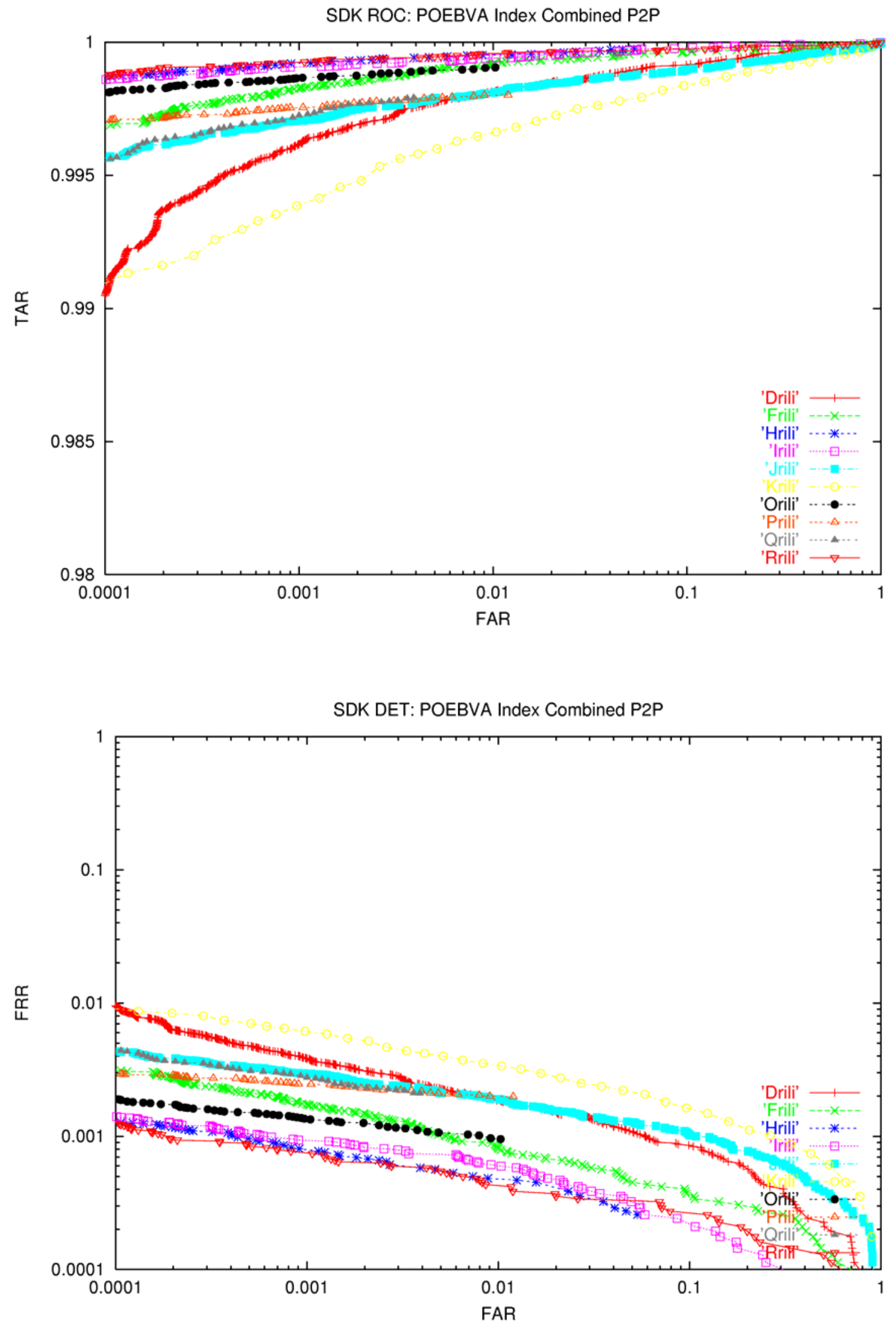